\title{
Metastatic renal cell cancer-is the outlook really improving?
}

\author{
Jonathan Waxman and Hilary Thomas
}

\begin{abstract}
Department of Clinical Oncology, Royal Postgraduate Medical School, Hammersmith Hospital, Du Cane Road, London W12 OHS, UK.
\end{abstract}

\section{Introduction}

Two thousand three hundred people die annually in the United Kingdom from renal cell carcinoma ${ }^{1}$ and the median survival for patients with metastatic disease is nine months. In the last decade, major developments in molecular biology and immunology have led to a spectacular improvement in the prognosis for a proportion of patients with this malignancy. In this article we review treatment options for metastatic renal cancer.

\section{Hormonal therapy}

In the 1970s there seemed to be real reason to hope that hormonal therapies might be effective for renal cell carcinoma and these hopes came from empirical observations of the effects of treatment in animals. Renal cell cancer in the Syrian golden haired hamster was shown to regress following orchiectomy and from this model hormonal therapies developed.

\section{Steroid hormone receptors}

Renal cell carcinoma contains receptors for steroid hormones and these include dihydrotestosterone, 17 beta oestradiol and progesterone. In one series 11 of 55 renal cancers were oestrogen receptor positive, 4 of 55 progesterone receptor positive and 10 of 53 testosterone receptor positive. ${ }^{2}$ In a second series, twelve of 62 tumours assayed for steroid hormone binding were found to contain dihydrotestosterone receptors. ${ }^{3}$ In another series of 41 renal carcinomas, 30 were androgen receptor positive, 11 oestrogen receptor positive and 11 progesterone receptor positive. In this series survival directly correlated with receptor positivity

Correspondence: J. Waxman M.D., B.Sc., M.R.C.P. Received: 29 January 1990 and those patients whose tumours expressed more than one receptor survived for longer than those who were receptor negative. ${ }^{4}$ In another series 16 of 19 patients' tumours were testosterone receptorpositive, one of 19 oestrogen receptor-positive and 20 were dihydrotestosterone receptor-positive. In these patients the level of dihydrotestosterone positivity directly correlated with clinical stage and the more advanced tumours had higher levels. Receptor status was examined in the normal kidney and a virtual concordance of positivity was found when tumour was compared with normal tissue. ${ }^{5}$

\section{Hormonal treatment}

A number of different hormonal therapies have been applied to the management of patients with metastatic renal cell cancer. Their attractiveness as a therapy for malignant disease lies in their comparative lack of toxicity as compared to cytotoxic chemotherapy or biological agents. Amongst the first to be used was medroxyprogesterone acetate and in an initial report a response rate of $27 \%$ was described by Julian Bloom. ${ }^{6}$ Because of this encouraging finding medroxyprogesterone acetate has been applied in different dosages and schedules to large numbers of patients. At a dosage of $500 \mathrm{mg}$ given intramuscularly daily for 6 weeks and thereafter twice weekly, three of 20 patients were seen to have responded. In this study tumour ploidy was assessed and it was found that those patients who responded had diploid tumours. ${ }^{7}$ In a group of 18 patients with advanced disease, medroxyprogesterone acetate was given at a dosage of $800 \mathrm{mg}$ intramuscularly weekly and no responses were seen. ${ }^{8}$ Twenty one patients were treated with $500-1000 \mathrm{mg}$ daily intramuscularly and one partial response was seen. ${ }^{9}$ Megesterol acetate was used to treat 85 patients with metastatic renal cell carcinoma at a dosage of $\mathbf{4 0} \mathrm{mg}$ thrice daily and four responded. ${ }^{10}$ These studies have considered the activity of the prostestogens in terms of tumour 
responsiveness. However, there are additional effects that are important and these relate to the anabolic qualities of this group of compounds which lead to increased weight and appetite which are welcomed by patients.

Flutamide is a pure antiandrogen without central affects which competitively binds to the androgen receptor. Twenty eight patients were treated with a dosage of $250 \mathrm{mg}$ of flutamide thrice daily orally; 25 patients were assessable and one had a partial response. $^{2}$

Because of the finding of oestrogen receptors within renal cell carcinomas tamoxifen has been used and at a dose of $20 \mathrm{mg}$ twice daily, responses were reported in 8 of 79 patients. ${ }^{11}$

\section{Cytotoxic chemotherapy}

Among agents considered to be effective in the treatment of renal cell carcinoma, vinblastine and $\mathrm{CCNU}$ are the most active. However, the order of response is low at less than $10 \% .{ }^{12}$ In order to improve upon the results obtained, these agents have been applied in unconventional schedules and in combination. CCNU at a dosage of $120 \mathrm{mg} / \mathrm{m}^{2}$ was given on day one and vinblastine at a dosage of $0.1 \mathrm{mg} / \mathrm{kg}$ on days 1 and 8 of a 6-week treatment cycle. No responses were seen in 15 patients. ${ }^{13}$ Vinblastine was given as an infusion at a dosage of $1.5 \mathrm{mg} / \mathrm{m}^{2}$ daily for 5 days, three weekly to 14 patients one of whom responded. ${ }^{14}$ Methotrexate given in combination with vinblastine and bleomycin with or without tamoxifen resulted in 10 partial responses of median duration 57 weeks in 34 treated patients. ${ }^{15}$ Vinblastine at a dosage of $5 \mathrm{mg} /$ $\mathrm{m}^{2}$ on day one, CCNU at $60 \mathrm{mg} / \mathrm{m}^{2}$ on day 2 and hydroxyurea at $400 \mathrm{mg} / \mathrm{m}^{2}$ twice daily on days 3 and 14 of a 4-week treatment cycle together with medroxyprogesterone acetate $1 \mathrm{~g}$ intramuscularly weekly led to three partial responses in 26 patients. $^{16}$

Other newer agents have been applied to the treatment of renal cell carcinoma with almost as little effect as more established therapies. Mitozantrone is an anthracycline with less cardiotoxicity than adriamycin, which does not result in significant nausea nor alopecia. Fifty eight patients with advanced renal cell carcinoma were treated with this agent at a dosage of $5 \mathrm{mg} / \mathrm{m}^{2}$ weekly; no responses were seen. ${ }^{17}$ 4-Demethoxydaunorubicin, an adriamycin derivative without significant cardiac toxicity, was given at a dosage of $12.5 \mathrm{mg} / \mathrm{m}^{2}$ three weekly to 19 patients, none of whom responded. ${ }^{18}$ Streptozocin was given to 18 evaluable patients at a dosage of $500 \mathrm{mg} / \mathrm{m}^{2}$ for 5 days every month and one partial response was reported. ${ }^{19}$

\section{Immunotherapy}

The comparative lack of response to cytotoxic and hormonal agents has resulted in a continued search for new treatments in an attempt to cure the patient with advanced disease. In this context the role of immunotherapy in the treatment of renal cell carcinoma has been investigated with relative enthusiasm.

\section{Interferons}

The initial reports of the effect of interferon in this disease came from Quesada in $1983 .^{20}$ This study used human leucocyte interferon derived from buffy coat leucocytes. Nineteen patients were treated with a daily dosage of 3 megaunits of leucocyte interferon and 5 partial responses were reported.

Leucocyte alpha interferon was used to treat 25 patients with metastatic renal cell carcinoma. Each patient received a dose of 3 megaunits daily; 2 complete and 4 partial responses were seen. The median time to response was 9 weeks and the median duration of response was 6 months. ${ }^{21}$ Leucocyte alpha interferon was used to treat 37 evaluable patients at a dose of 30 megaunits daily by three hourly intravenous infusion. The dosage was increased by 10 megaunits weekly until tolerance was reached and resulted in 4 partial responses. ${ }^{22}$ The advances of molecular biology have resulted in the availability of relatively large amounts of biologically pure interferon and subsequently, studies have appeared using recombinant interferon. Recombinant interferon was used at a dosage of between 3 and 36 megaunits intramuscularly daily; 4 complete and 36 partial responses were seen in 226 patients. ${ }^{23}$ Buzaid and Todd have summarized 17 clinical trials of 620 patients, 258 patients responded and 42 of these responses were complete. ${ }^{24}$ There seemed to be no evidence of any difference between the different forms of interferons; leucocyte, fibroblast, lymphoblast and recombinant interferons all having the same order of response. It also appears that there is no significant dose response relationship and one of the most commonly applied regimens that seems to have the optimal balance between side effects, efficacy, and ease of administration is interferon at a dosage of 3 megaunits thrice weekly subcutaneously. ${ }^{24}$

In vitro studies have demonstrated a greater antitumour effect of interferon gamma as compared to beta or alpha interferon. The activity of gamma interferon was investigated by Garnick $e t$ al. in a Phase 1/2 study; 41 patients were treated with either a daily 2 hour infusion or a 24 hour infusion of gamma interferon given for 7 days every 3 weeks; the dosage was increased from $10 \mathrm{mg} / \mathrm{m}^{2}$ 
to $3,000 \mathrm{mg} / \mathrm{m}^{2}$. Dose limiting toxicity occurred between 1,000 and $3,000 \mathrm{mg} / \mathrm{m}^{2}$ with one complete response and three partial responses. ${ }^{25}$ Interferons do have side effects, the most common of which are flu-like symptoms occurring approximately one hour after injection and lasting from 2 to 3 hours. These may be eased by simple agents such as aspirin given an hour prior to interferon administration. More significant side effects such as alopecia, marrow suppression and changes in hepatic and renal function are reported at all dosages and schedules of interferon administration.

\section{Interferons and chemotherapy}

The synergistic effects of interferon given with cytotoxic chemotherapy have been investigated; 24 patients were treated with vinblastine at a dosage of $0.15 \mathrm{mg}$ per kilogram weekly and buffy coated interferon at a dosage of 3 megaunits, 5 times weekly and led to 3 partial responses. ${ }^{26}$ Interferon alpha 2a at a dosage of 10 megaunits intramuscularly with vinblastine $0.075 \mathrm{mg} / \mathrm{kg}, 3$-weekly given to 20 patients or $0.1 \mathrm{mg} / \mathrm{kg}$ of vinblastine 3weekly was given to 18 patients and resulted in one complete and 16 partial responses. ${ }^{27}$

It would seem then that there is no synergistic effect between vinblastine and interferon and that the effects of the interferons are not exactly optimal in the management of this disease. The true complete response rate seems to be approximately $10 \%$ for a median duration of between 4 and 6 months.

\section{Adoptive immunotherapy}

Much of the original work in this field was pioneered by Rosenberg at the National Cancer Institute, Bethesda, Maryland. His initial studies were carried out in animals where he demonstrated that interleukin-2 alone or in combination with lymphokine-activated killer cells decreased the size of pulmonary and hepatic metastases from experimental tumours. ${ }^{28}$ In 1983 clinical trials began in patients with advanced disseminated cancer in whom conventional therapy had failed, and encouragingly high response rates were reported in solid tumours, unresponsive to conventional therapies. ${ }^{29,30}$

\section{Interleukin-2: mechanisms of action}

IL-2 is a chemically defined lymphokine, originally described as a T-cell growth factor causing proliferation of activated T-cells. It has been shown to lead to increased chemotaxis and cytotoxicity in certain subpopulations of cells including T-cells bearing the CD4 surface marker. In addition IL-2 induces the release of other lymphokines and activates natural killer cells, lymphokine-activated killer cells, tumoricidal macrophages and cytolytic T-cells. Amongst the lymphokines induced are gamma interferon and tumour necrosis factor. It has a short in vivo half-life but its persistence in serum is important for the induction of a clinical response. The effects of IL-2 are extremely complex and we only have a sketchy model for the interacting network of this cytokine's actions. It would seem that antibody interacts with an antigenpresenting cell, usually a monocyte or macrophage, several factors are then released which, along with the antigen, stimulate surrounding cells, including CD4 positive T-cells, to release IL-2. IL-2 interacts with a further receptor and causes upregulation of IL-2 receptors on T-cells and the release of other lymphokines. From experimental and clinical data, high dosages of IL-2 appear to have the same effects as IL-2 given with LAK-cells.

Any current attempt to explain the interactions of IL-2, effector cells and other cytokines is simplistic because a number of interacting and complex mechanisms seem to be involved. Furthermore, it may be that different processes are involved in the mechanisms of tumour cytotoxicity in different malignancies and in different organs involved with metastatic disease from the same primary cancer. The effect of IL-2 may be a humoral one as a result of cytokine activity, a cellular cytotoxic effect involving predominantly $\mathrm{T}$-cells or an indirect effect on vascular endothelium resulting in ischaemic tumour necrosis.

\section{Interleukin 2: dosage schedules}

The attainment of the 'correct' dosage regimens and routes of administration of IL-2 in humans has been expedited by animal work. Initially, IL-2 was used in high dosages, as repeated bolus injections, alone or with LAK-cells. After an intravenous bolus IL-2 has a distribution half-life of 7 to 10 minutes and a clearance half-life of 30 to 60 minutes. The establishment of correct dosage schedules has been virtually serendipitous where side effects have been titrated against clinical responses. Recently a number of studies have been carried out involving low dose recombinant IL-2 and the results have been encouraging. It would appear that achieving toxicity with IL-2 therapy is not a prerequisite for response. ${ }^{31,32}$

In an attempt to produce regimens with less toxicity rIL-2 has been given as a continuous infusion. ${ }^{33}$ Increased experience of biological response modifiers led to the view that 'area under the curve' was important but not the maximum tolerated dose, unlike conventional chemotherapy. Furthermore, because continuous infusion IL-2 results in constant exposure of cells to cytokines, this method of administration should theoretically 
be more effective than bolus dosage regimens. Using continuous infusion regimens West et al. have produced comparable response rates with significantly reduced toxicity. ${ }^{33}$

\section{Interleukin 2: regional perfusion}

'Cell trafficking' is an important aspect of the effectiveness of cytokine therapy for cancer. If the fate of LAK-cells in the body is traced they reach the lungs within a couple of hours of injection and within 24 hours have been taken up by the reticuloendothelial system. Consequently, relatively few of these effector cells actually reach the tumour where they are most likely to be effective. On this basis local routes of administration of rIL-2 have been used in the hope that improved localization of therapy will result in better responses. There are relatively little data in this field and early results are disappointing. ${ }^{34}$

\section{Interleukin-2: treatment results}

As shown in Table I, response rates in renal cell carcinoma of between 20 and $40 \%$ have been reported. Those patients with a high ECOG performance status, small bulk disease and without cerebral or bony metastases are likely to do best. Patients without these prognostic factors have only a 10 or $15 \%$ chance of responding to therapy. Responses are durable and about $10 \%$ of those patients treated relatively early in the era of IL-2 therapy have had sustained clinical remissions which are currently maintained. Partial responses to IL-2 also appear to last longer than those achieved with conventional therapy.

\section{Interleukin 2: side effects}

IL-2 affects endothelium causing a 'vascular leak syndrome' where lymphoid cells and other peripheral blood components migrate into extravascular tissues. This phenomenon explains many of the side effects of IL-2. One of the most commonly observed features of IL-2 treatment is fluid retention which usually manifests as cerebral and pulmonary oedema. Myocardial infarction and ascites have also been reported.$^{35,36}$ Similar side effects occur with both continuous infusion and bolus therapy but are less common with the former. Fevers, nausea, vomiting, eosinophilia and anaemia are also seen with both forms of treatment. Early work at the NCI was accompanied by disastrous toxicity and a high proportion of patients required admission to intensive care. The realization that toxicity is not essential to efficacy and the use of continuous infusion IL-2 in outpatients has led to a dramatic reduction in both the cost and toxicity of therapy.

\section{Interleukin 2: the future}

The most recent studies performed by Rosenberg and colleagues have investigated the activity of tumour-infiltrating lymphocytes extracted from resected tumours, whose growth has been stimulated in vitro with IL-2 $2^{37}$ and then re-infused into patients, but it is too early to comment on the results of this approach. ${ }^{38}$ Other cytokines act synergistically with IL-2 and projected future trials will investigate treatment where the administration of tumour necrosis factor is followed by recombinant IL-2 and alpha interferon. This is a relatively non-toxic regimen which does not necessitate inpatient care and shows great promise if the results seen in animal models are continued in man.

Most studies of IL-2 have been carried out in the presence of gross bulk disease. Logically cytokines should be more effective in the situation where there is minimal residual disease. A recent trial in the treatment of acute myeloid leukaemia has shown that IL-2 can be used alongside intensive chemoradiotherapy in patients with minimal residual disease. ${ }^{39}$ If this translates into improved remission duration or cure, the next logical step would be the application of this approach to solid tumours with the use of IL-2 in the adjuvant setting, in early stage renal cancer.

\section{Conclusion}

The prospect for the patient with renal cell cancer has definitely improved as a result of the treatment

Table I Response rates in renal cell carcinoma

\begin{tabular}{lcccc}
\hline Study & $\begin{array}{c}\text { Complete } \\
\text { response }\end{array}$ & $\begin{array}{c}\text { Partial } \\
\text { response }\end{array}$ & $\begin{array}{c}\text { Minimal } \\
\text { response }\end{array}$ & $\begin{array}{c}\text { Patients } \\
\text { treated }\end{array}$ \\
\hline Rosenberg et al. ${ }^{30}$ & 4 & 8 & 7 & 36 \\
${\text { West } \text { et al. }{ }^{33}}_{\text {Eberlein } \text { et al. }{ }^{32}}$ & 1 & 2 & - & 6 \\
\hline
\end{tabular}


advances of the last five years. In a significant proportion of patients, metastatic disease can be cured and a better future is promised as cytokine treatment is further refined.

\section{References}

1. Cancer Statistics. Cause 1987. DH2 No. 14. HMSO, 1989.

2. Ahmed, T., Benedette P., Yagoda, A. et al., Estrogen, progesterone and androgen-binding sites in renal cell carcinoma. Cancer 1984, 54: 477-481.

3. Pizzocaro, G., Piva, L., Salvioni, R. et al. Adjuvant medroxyprogesterone acetate and steroid hormone receptors in category MO renal cell carcinoma. An interim report of a prospective randomized study. $J$ Urol 1986, 135: 18-21.

4. Nakano, E., Tada, Y., Fujioka, H. et al. Hormone receptor in renal cell carcinoma and correlation with clinical response to endocrine therapy. J Urol 1984, 132: 240-245.

5. Noronha, R.F.X.\& Rao, B.R. Increased dihydrotestosterone receptor levels in high-stage renal adenocarcinoma. Cancer 1985, 56: 134-137.

6. Bloom, H.J.G. Medroxyprogesterone acetate (Provera) in the treatment of metastatic renal cell cancer. Br J Cancer 1971, 25: $250-265$.

7. Ljungberg, B., Tomic, R. \& Roos, G. Deoxyribonucleic acid content and medroxyprogesteron acetate treatment in metastatic renal cell carcinoma. J Urol 1989, 141: 1308-1310.

8. Gottesman, J.E., Crawford, E.D., Grossman, H.B., Scardino, P. \& McCracken, J.D. Infarction-nephrectomy for metastatic renal carcinoma. Southwest Oncology Group Study. Urology 1985, 25: 248-250.

9. Kjaer, M. \& Frederiksen, P.L. High-dose medroxyprogesterone acetate in patients with renal adenocarcinoma and measurable lung metastases: A phase II study. Cancer Treat Rep 1986, 70: 431-432.

10. Hahn, R.G., Bauer, M. \& Wolter, J. et al. Phase II study of single agent therapy with megesterol acetate, VP-16-213, cyclophosphamide, and dianhydrogalactitol in advanced renal cell cancer. Cancer Treat Rep 1979, 63: 513-515.

11. Al-Sarraf, M., Eyre, H., Bonnet, J. et al. Study of tamoxifen in metastatic renal cell carcinoma and the influence of certain prognostic factors. A Southwest Oncology Group Study. Cancer Treat Rep 1981, 65: 447-451.

12. Dekernion, J.B. Treatment of advanced renal cell carcinoma - traditional methods and innovative approaches. $J$ Urol 1983, 130: 2-7.

13. Sommer, H.H., Fossa, S.D. \& Lien, H.H. Combination chemotherapy of advanced renal cell cancer with CCNU and vinblastine. Cancer Chemother Pharmacol 1985, 14: 277-278.

14. Tannock, I.F. \& Evans, W.K. Failure of 5-day vinblastine infusion in the treatment of patients with renal cell carcinoma. Cancer Treat Rep 1985, 69: 227-228.

15. Bell, D.R., Aroney, R.S., Fisher, R.J. \& Levi, J.A. High dose methotrexate with leucovorin rescue vinblastine and bleomycin with or without tamoxifen in metastatic renal cell carcinoma. Cancer Treat Rep 1984, 68: 587-590.

16. Brubaker, L.H., Troner, M.B. \& Birch, R. Advanced adenocarcinoma of the kidney: Therapy with lomustine, vinblastine, hydroxyurea, and medroxyprogesterone acetate and regression analysis of factors relating to survival. Cancer Treat Rep 1983, 67: 741-742.

17. Garns, R.A., Nelson, O. \& Birch, R. Phase II evaluation of mitoxantrone in advanced renal cell carcinoma: A Southeastern Cancer Study Group Trial. Cancer Treat Rep, 70, 921-922.

18. Scher, H.I., Yagoda, A., Ahmed, T., Budman, D., Sordillo, P. \& Watson, R.C. Phase-II trial of 4-demethoxydaunorubicin (DMDR) for advanced hypernephroma. Cancer Chemother Pharmacol 1985, 14: 79-80.

19. Licht, J.D. \& Garnick, M.B. Phase II trial of streptozocin in the treatment of advanced renal cell carcinoma. Cancer Treat Rep 1987, 71: 97-98.
20. Quesada, J.R., Swanson, D.A., Trindade, A. \& Gutterman, J.U. Renal cell carcinoma: antitumour effects of leukocyte interferon. Cancer Res 1983, 43: 940-947.

21. Fujita, T., Haruyosi, A., Naide, Y. et al. Antitumour effects of human lymphoblastoid interferon on advanced renal cell carcinoma. J Urol 1988, 139: 256-258.

22. Eisenhauer, E.A., Silver, H.K., Venner, P.M., Thirwell, M.P., Weinerman, B. \& Coppin, C.M.L. Phase II study of high dose weekly intravenous human lymphoblastoid interferon in renal cell carcinoma. A Study of the National Cancer Institute of Canada Clinical Trials Group. Br J Cancer 1987, 55: $541-542$.

23. Umeda, T. \& Nijima, T. Phase II study of alpha interferon on renal cell carcinoma. Summary of three collaborative trials. Cancer 1986, 58: 1231-1235.

24. Buzaid, A.C. \& Todd, M.B. Therapeutic options in renal cell carcinoma. Semin Oncol 1989, 16: 12-19.

25. Garnick, M.B., Reich, S.D., Maxwell, B., Coval-Goldsmith, S., Richie, J.P. \& Rudnick, S.A. Phase I/II study of recombinant interferon gamma in advanced renal cell carcinoma. $J$ Urol 1988, 139: 251-255.

26. Figlin, R.A., deKernion, J.B., Maldazys, J. \& Sarna, G Treatment of renal cell carcinoma with (human leukocyte) interferon and vinblastine in combination: a phase I-II trial. Cancer Treat Rep 1985, 69: 263-267.

27. Bergerat, J.P., Herbrecht, R., Dufour, P. et al. Combination of recombinant interferon Alpha-2A and vinblastine in advanced renal cell cancer. Cancer 1988, 62: 2320-2324.

28. Rosenberg, S.A., Mule, J.J., Spiess, P.J., Reichert, C.M. \& Schwarz, S.L. Regression of established pulmonary metastases and subcutaneous tumour mediated by the systemic administration of high-dose recombinant interleukin 2.J Exp Med 1985, 161: 1169-1188.

29. Rosenberg, S.A., Lotze, M.T., Muul, L.M. et al. Observations on the systemic administration of autologous lymphokine-activated killer cells and recombinant interleukin-2 to patients with metastatic cancer. $N$ Engl $J$ Med 1985, 313: 1485-1492.

30. Rosenberg, S.A., Lotze, M.T., Muul, L.M. et al. A progress report on the treatment of 157 patients with advanced cancer using lymphokine-activated killer cells and interleukin 2 or high dose interleukin 2 alone. $N$ Engl J Med 1987, 316: 889-897.

31. Mitchell, M.S., Kempf, R.A., Harel, W. et al. Effectiveness and tolerability of low dose cyclophosphamide and low-dose intravenous interleukin-2 in disseminated melanoma. J Clin Oncol 1988, 6: 409-424.

32. Eberlein, T.J., Schoof, D.D., Jung, S.E. et al. A new regime of interleukin 2 and lymphokine-activated killer cells. Efficacy without significant toxicity. Arch Intern Med 1988, 148: 2571-2576.

33. West, W.H., Tauer, K.W., Yannelli, J.R. et al. Constantinfusion recombinant interleukin-2 in adoptive immunotherapy of advanced cancer. N Engl J Med 1987, 316: 898-905

34. Merchant, R.E., Merchant, L.H., Cook, S.H. et al. Intralesional infusion of lak cells and recombinant interleukin-2 for the treatment of patients with malignant brain tumours. Neurosurgery 1988, 23: 725-732.

35. Thomas, H., Vallis, K., Williams, G. \& Waxman, J. Interleukin- 2 induced ascites in the treatment of renal cell cancer. Br J Urol. In press.

36. Osanto, S., Cluitmans, F.H., Franks, C.R. et al. Myocardial injury after interleukin-2 therapy. Lancet 1988, ii: 8601 : 48-49. 
37. Rosenberg, S.A., Packard, B.S., Aebersold, P.M. et al. Use of tumour-infiltrating lymphocytes and interleukin-2 in the immunotherapy of patients with metastatic melanoma: A preliminary report. $N$ Engl J Med 1988, 319: 1676-1680.

38. Rosenberg, S.A. The development of new immunotherapies for the treatment of cancer using interleukin-2. Ann Surg $1988,208,121-135$.
39. Gottlieb, D.J., Brenner, M.K., Heslop, H.E. et al. A phase I clinical trial of recombinant interleukin 2 following high dose chemoradiotherapy for haematological malignancy: applicability to the elimination of minimal residual disease. $\mathrm{Br} J$ Cancer 1989, 60: 610-615. 